\title{
Level of UV-B radiation influences the effects of glyphosate-based herbicide on the spotted salamander
}

\author{
Nicholas A. Levis ${ }^{1} \cdot$ Jarrett R. Johnson $^{1}$
}

Accepted: 11 March 2015

(C) Springer Science+Business Media New York 2015

\begin{abstract}
Glyphosate-based herbicides are the number one pesticide in the United States and are used commonly around the world. Understanding the affects of glyphosatebased herbicides on non-target wildlife, for example amphibians, is critical for evaluation of regulations pertaining to the use of such herbicides. Additionally, it is important to understand how variation in biotic and abiotic environmental conditions, such as UV-B light regime, could potentially affect how glyphosate-based herbicides interact with non-target species. This study used artificial pond mesocosms to identify the effects of generic glyphosatebased herbicide (GLY-4 Plus) on mortality, cellular immune response, body size, and morphological plasticity of larvae of the spotted salamander (Ambystoma maculatum) under conditions that reflect moderate $\left(\mathrm{UV}_{\mathrm{M}}\right)$ and low $\left(\mathrm{UV}_{\mathrm{L}}\right)$ UV-B light regimes. Survival within a given UV-B level was unaffected by herbicide presence or absence. However, when herbicide was present, survival varied between UV-B levels with higher survival in $\mathrm{UV}_{\mathrm{M}}$ conditions. Herbicide presence in the $\mathrm{UV}_{\mathrm{M}}$ treatments also decreased body size and reduced cellular immune response. In the $\mathrm{UV}_{\mathrm{L}}$ treatments, the presence of herbicide increased body size and affected tail morphology. Finally, in the absence of herbicide, body size and cellular immune response were higher in $\mathrm{UV}_{\mathrm{M}}$ treatments compared to $\mathrm{UV}_{\mathrm{L}}$ treatments. Thus, the effects of herbicide on salamander
\end{abstract}

Electronic supplementary material The online version of this article (doi:10.1007/s10646-015-1448-2) contains supplementary material, which is available to authorized users.

Nicholas A. Levis

nicholasalevis@gmail.com

1 Department of Biology, Western Kentucky University, Bowling Green, KY 42101, USA fitness were dependent on UV-B level. As anthropogenic habitat modifications continue to alter landscapes that contain amphibian breeding ponds, salamanders may increasingly find themselves in locations with reduced canopy cover and increased levels of UV light. Our findings suggest that the probability of surviving exposure to the glyphosate-based herbicide used in this study may be elevated in more open canopy ponds, but the effects on other components of fitness may be varied and unexpected.

Keywords Amphibian decline - Aquatic ecology · Ecotoxicology $\cdot$ Pesticide $\cdot$ Roundup

\section{Introduction}

Concern regarding the susceptibility of amphibians to environmental change has led to decades of research aimed at elucidating the anthropogenic causes of population declines (Houlahan et al. 2000; Stuart et al. 2004). Commonly, authors suggest that habitat destruction or alteration plays a large role in the decline of amphibian populations (Gallant et al. 2007). Additionally, other factors such as diseases and parasites have been implicated in declines (Kiesecker 2011; Blaustein et al. 2012). The effects of environmental pollutants have also been widely investigated and while the extent to which anthropogenic toxins are affecting amphibian populations at a global scale remains uncertain (Davidson 2004; Davidson and Knapp 2007; Bradford et al. 2011; Edge et al. 2012), the negative effects of such toxins on experimental amphibian populations has been well-established (Egea-Serrano et al. 2012). The importance of interactions between environmental toxins and other biotic and abiotic factors has also been welldemonstrated (e.g. Chen et al. 2004; Kerby et al. 2011), 
prompting continued investigation regarding the potential for toxins to contribute to global patterns of decline.

Glyphosate-based herbicides are the most widely applied types of herbicide in the world and can affect amphibians and damage aquatic systems (e.g. Relyea et al. 2005; Govindarajulu 2008; Jones et al. 2011). Many of these herbicide formulations contain the surfactant polyethoxylated tallowamine (POEA) which has resulted in their classification as moderately to highly toxic in laboratory, experimental mesocosm, and pond enclosure experiments (Baylis 2000; Chen et al. 2004; Edginton et al. 2004; Howe et al. 2004; Wojtaszek et al. 2004; Relyea et al. 2005; Bernal et al. 2009; Jones et al. 2011). These herbicide formulations often interact with other abiotic and biotic factors such as high $\mathrm{pH}$ and predator chemical cues (Chen et al. 2004; Edginton et al. 2004; Wojtaszek et al. 2004; Relyea 2005a). However, because glyphosate has a half-life of only 7.5 days and sediment readily removes POEA from the water column (Wang et al. 2005; Barolo 1993), their potential for negative effects on amphibians might be reduced in certain environmental conditions. Glyphosate-based herbicides are widely used, can change ecosystems, and interact with other environmental factors; thus, amphibian responses to application of these herbicides warrants continued investigation in various ecological contexts (i.e. in combination with a variety of biotic or abiotic factors).

Increased ultraviolet radiation, a result of ozone depletion, can have significant effects on amphibian populations (Blaustein et al. 2003). The current depletion of stratospheric ozone by production of chlorofluorocarbons and other chemicals has led to long-term increases in ultraviolet radiation (Cockell and Blaustein 2000; Blaustein et al. 2003). Ozone depletion has already resulted in significantly increased levels of UV-B (280-315 nm) in both tropical and temperate regions (Kerr and McElroy 1993; Herman et al. 1996; Middleton et al. 2001).

Amphibians occupy a variety of habitats ranging from flowing streams to small ephemeral pools. The penetration of UV radiation into these habitats varies with amount of tree cover, organic matter, water $\mathrm{pH}$, and geographic location (Crump et al. 1999b; Flint and Caldwell 1998; Cordero et al. 2013). Changes to UV-B radiation inputs into freshwater systems can elicit complex responses (e.g. feedback loops involving water transparency, primary production, bacteria, zooplankton, and vertebrate predators; Williamson 1995; Hader et al. 2007, 2011), and affect amphibian growth, development, and ultimately fitness depending on the specific attributes of the system (reviewed by Croteau et al. 2008). Habitat changes through human activities, changing climate, and forestry diseases can alter the input of UV-B into a system (Worrall and Harrington 1988; Krasny and Whitmore 1992). Increasing the input of UV-B into a system could have a variety of negative effects on amphibians (Broomhall et al. 2000; Tietge et al. 2001; Bancroft et al. 2008a). For example, UV-B can breakdown a contaminant into more or less toxic forms (Zaga et al. 1998; Shayeghi et al. 2012). Lund-Høie and Friestad (1986) demonstrated that glyphosate is photolytic and breaks down more rapidly in sunlight, suggesting that high UV-B conditions could potentially breakdown the herbicide into less toxic compounds. As expected in this scenario, a recent study by Puglis and Boone (2011) found little difference in mortality of green frog (Lithobates clamitans) tadpoles exposed to glyphosate-based herbicide under UV-B present and absent treatments in the laboratory. However, the interaction among glyphosate-based herbicides and UV-B exposure needs further study under more realistic conditions that contain simple factors such as phytoplankton growth, organic matter decomposition, and turbidity, that laboratory studies cannot provide (Govindarajulu 2008).

Despite their potential to negatively affect amphibians, glyphosate-based herbicide and UV-B have received little examination together under semi-natural conditions. Furthermore, previous studies have focused primarily on anuran larvae when investigating these stressors and given much less attention to caudates. Since the spotted salamander, Ambystoma maculatum, is predominantly a forest species, has a large geographic range (Petranka 1998), demonstrates environmentally-induced phenotypes (Urban $2008,2010)$ and breeds in ponds with a variety of light regimes, its larvae serve as an ideal model to investigate potential consequences of glyphosate-based herbicide and UV-B. The aims of this study were to evaluate the interactive effects of glyphosate-based herbicide and two ecologically relevant UV-B levels on a larval salamander. Specifically, we measured (1) mortality, (2) cellular immune response, (3) body size, and (4) tail morphology because these endpoints can have important effects on the fitness of salamanders. We predicted that the absence of glyphosate-based herbicide and lower UV-B levels would result in the highest fitness (i.e. most survival, greatest body size and cellular immune response, and "normal" morphology) because these conditions are expected to be the least stressful.

\section{Materials and methods}

\section{Animal collection and rearing}

We collected eight $A$. maculatum egg masses from a pond near Western Kentucky University's Green River Preserve in Hart County, KY, on March 20-21, 2013. Clutches were held separately in outdoor wading pools covered with a 
mesh screen. Larvae began hatching on April 20 and all larvae had emerged from eggs by May 1. After hatching, larvae were fed a combination of wild collected zooplankton and commercial brine shrimp (Artemia spp.) ad libitum.

\section{Mesocosm preparation}

Plastic mesocosms (i.e. $1200 \mathrm{~L}$ cattle tanks) were filled between 11 and 16 February, 2013 with $\sim 835 \mathrm{~L}$ of municipal water, and then $500 \mathrm{~g}$ of mixed deciduous leaf litter (Acer/Quercus spp.) and $80 \mathrm{~g}$ of rabbit chow were added to serve as initial nutrient sources. An initial $280 \mathrm{~mL}$ aliquot of concentrated zooplankton, phytoplankton, and periphyton collected from nearby ponds was also added to each tank. Soil was not added to the mesocosms because adding soil has no effect on the toxicity of glyphosate-based herbicide (Roundup ${ }^{\circledR}$ ) under mesocosm conditions (Relyea 2005b). We then added a water conditioner (Kordon AmQuel@) to remove chlorine and chloramines that are potentially deadly to amphibians. Subsequently, we added another $205 \mathrm{~mL}$ of concentrated plankton to ponds between 1 March and 30 April 2013 for a total of $485 \mathrm{~mL}$. After the final aliquot of plankton was added, communities developed for another $18 \mathrm{~d}$ prior to the addition of larvae. In the period between tank preparation and addition of larval salamanders, 22 American toad (Anaxyrus americanus) tadpoles were added to each tank to maintain water clarity via control of algal growth. By the start of the experiment, all toad tadpoles had metamorphosed and been removed or perished. On 8 May 2013 (defined as day 0; $\sim 80$ days after filling the tanks), we added 15 larval salamanders ( $\sim 2$ week post-hatch) to each mesocosm and haphazardly selected five additional individuals from each clutch to provide a pre-experiment body size estimate $(2.06 \pm 0.05 \mathrm{~cm}$ total length). We chose to use a low density of fifteen salamander larvae to reduce or eliminate any potential effects of competition on mortality and morphology (Relyea 2004). After approximately 2 weeks (23 May 2013), we added 26 Hyla chrysoscelis tadpoles to each tank to help control algal growth and maintain water clarity. The Hyla tadpoles were too large for the salamanders to consume, and are assumed not to have been used as a food source. As frogs metamorphosed, they were released.

\section{Experimental design}

We used a randomized Graeco-Latin Squares design (Fig. S1) to generate eight replicates of four treatments that differed with respect to herbicide level and UV-B exposure. The eight clutches were used to populate each of the eight replicates separately for a total of 32 total experimental units. As described below, the four treatments were as follows: (1) 'moderate UV' and 'herbicide present' $\left(\mathrm{UV}_{\mathrm{M}} / \mathrm{H}+\right)$, (2) 'moderate UV' and 'herbicide absent' $\left(\mathrm{UV}_{\mathrm{M}} / \mathrm{H}-\right)$, (3) 'low UV' and 'herbicide present' $\left(\mathrm{UV}_{\mathrm{L}} /\right.$ $\mathrm{H}+)$, and (4) 'low UV' and 'herbicide absent' $\left(\mathrm{UV}_{\mathrm{L}} / \mathrm{H}-\right)$.

The family-level relationships of individuals were maintained by not mixing individuals across mesocosms, as is perhaps a more common approach (e.g. Relyea 2003, 2004, 2006; Relyea and Hoverman 2008; but see Bridges and Semlitsch 2001). In other words, we only used a single clutch to populate each replicate of the experimental treatments. Therefore, we are asserting that we have eight replicates that are each comprised of separate families of salamanders. We maintained separate families in this experiment for several reasons. First and foremost, we were interested in partitioning the random effects of families ("random" in the context of mixed effects regression, with "fixed" effects being the treatments [see 'Statistical Analyses' section]) so that we would have more power to detect the fixed effects. Secondly, we did not mix clutches because of the potential for clutch-specific differences in responses to contaminants. If we had mixed clutches, we would lose the ability to ascertain the extent to which our observed effects were influenced by clutch-specific effects. Lastly, one of our goals was to understand phenotypic plasticity, which is defined as the ability of individuals of identical genotypes to express phenotypes differently in response to environmental variation (Gilbert and Epel 2009). It would have been impossible to measure plasticity if we could not determine which individuals were genetically most similar (i.e., full siblings).

Larvae were exposed to two levels of UV-B, moderate $\left(U_{\mathrm{M}}\right)$ or low $\left(\mathrm{UV}_{\mathrm{L}}\right)$, which represented ecologically relevant levels of UV-B in open canopy/forest edge ponds and closed canopy ponds, respectively (Fig. 1). Two types of UV-filtering films were attached to a $2.54 \mathrm{~cm}$ diameter PVC pipe, the pipe was placed across the center of each tank, and films were then tightened around the outside of each mesocosm and held in place by wooden panels stapled to the film and tanks. In essence, this design resembled a very squat "fly" tent and allowed air circulation in the mesocosms (Fig. S2). The acetate film created the moderate UV-B treatment $\left(\mathrm{UV}_{\mathrm{M}}\right)$, and transmitted between 57 and $77 \%$ of light at 280 and $315 \mathrm{~nm}$, respectively (the extreme ends of the UV-B spectrum). The Duralar ${ }^{\circledR}$ film created the low UV-B treatment $\left(\mathrm{UV}_{\mathrm{L}}\right)$, and transmitted $\sim 2 \%$ of light at $315 \mathrm{~nm}$ and attenuated to $<0.3 \%$ at $280 \mathrm{~nm}$. We verified the percent transmission of UV-B using a Perkin Elmer Lambda XLS + spectrophotometer. In addition, both films transmitted equivalent amounts of all other wavelengths. Therefore, the amount of UV-B transmitted by these films was comparable to those used in previous studies (Blaustein et al. 1994). To account for 


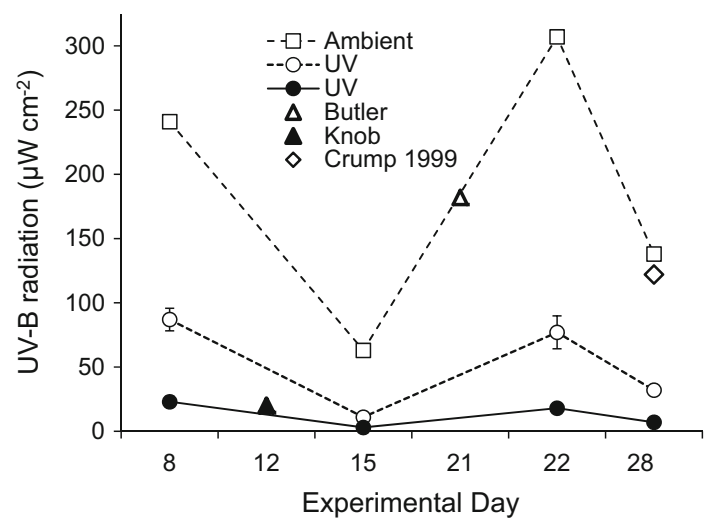

Fig. 1 UV-B values for ambient UV-B (open squares), the two UV$\mathrm{B}$ treatment types $\left(\mathrm{UV}_{\mathrm{M}}\right.$ : open circles; $\mathrm{UV}_{\mathrm{L}}$ : closed circles), two natural ponds with different canopy characteristics (open triangle and closed triangle), and a previous study with an open canopy pond (open diamond). On day 15, the sky was overcast and very cloudy such that little UV-B reached the tanks. Butler and Knob ponds were open and closed canopy measurements, respectively, that were used as natural comparisons for $\mathrm{UV}_{\mathrm{M}}$ and $\mathrm{UV}_{\mathrm{L}}$, respectively. Measurements for this study were taken between 1100 and $1400 \mathrm{~h}$ at the water's surface. From Crump et al. (1999a), "Experiments were conducted in an area... where differential shading could be avoided." Our experimental treatments were somewhat conservative in their variation, but were within the range of UV-B levels encountered in nearby natural ponds

potential changes in UV-B transmission due to weathering during experimental duration, we measured the percent UV-B transmission weekly throughout the study period.

UV-B levels of eight randomly selected tanks (4 per film type) were measured above the tanks outside the film, just below $(\sim 3 \mathrm{~cm})$ the water's surface, and $\sim 40 \mathrm{~cm}$ below the water's surface weekly between 1100 and $1300 \mathrm{~h}$ using a Solarmeter ${ }^{\circledR}$ model 6.2 UV meter (Solartech Inc., Harrison Twp., MI). Surface temperature and $\sim 40 \mathrm{~cm}$ submerged temperatures were also taken in the selected tanks to ensure that only UV-B level differed between film types. For submerged UV-B measurements, the meter was held in a clear Ziplock ${ }^{\mathrm{TM}}$ bag. Twenty sample measurements were taken to account for the reduction in percent transmission by the bag compared to ambient levels. Bagged readings were $88 \pm 0.6 \%$ of ambient UV-B and were corrected prior to being reported.

UV-B levels varied between $U_{M}$ and $U_{L}$ treatments at the water's surface (Fig. 1), but all UV-B measurements attenuated to $0 \mu \mathrm{W} \mathrm{cm}{ }^{-2} 40 \mathrm{~cm}$ below the surface. On average, $\mathrm{UV}_{\mathrm{M}}$ treatments had $\sim 4 \times$ higher levels of UV-B than $\mathrm{UV}_{\mathrm{L}}$ treatments and $\sim 4 \times$ lower UV-B levels than ambient (12 vs. 51 vs. $186 \mu \mathrm{W} / \mathrm{cm}^{2}$ ). Thus, $\mathrm{UV}_{\mathrm{M}}$ and $\mathrm{UV}_{\mathrm{L}}$ treatments had $\sim 27$ and $\sim 6 \%$, respectively, of ambient UV-B at water's surface. These surface UV-B levels were within naturally observed values for open/edge and closed canopy ponds (Fig. 1). Our $\mathrm{UV}_{\mathrm{M}}$ treatments were conservative estimates of open canopy conditions and more likely reflect those of a pond near a forest's edge. Water temperature did not differ much between the two UV-B treatments, but did vary between the water's surface and the tank bottom (Table S1).

There were two levels of herbicide treatment: herbicide added $(\mathrm{H}+)$ or herbicide not added $(\mathrm{H}-)$. The herbicide treatments were applied on 9 May 2013 (day 1). We used the most common formulation of glyphosate-based herbicide sold in the area surrounding the study site, GLY-4 Plus $^{\mathrm{TM}}$ (Universal Crop Protection Alliance, LLC, Eagan, MN, USA).This formulation contains $41 \%(480 \mathrm{~g} / \mathrm{L})$ active ingredient glyphosate in the form of its isopropylamine salt which equates to $356 \mathrm{~g} / \mathrm{L}$ of the acid glyphosate. This formulation also contains the surfactant POEA. We added $7 \mathrm{~mL}$ of the commercial formulation to the mesocosms in order to attain the nominal acid equivalent (a.e.) concentration of $3 \mathrm{mg}$ a.e./L which is within the range of actual worse-case scenarios seen in nature (1.7-5.2 $\mathrm{mg}$ a.e./L; Edwards et al. 1980) that can induce morphological changes in some anuran species (Relyea 2012). However, this concentration is lower than laboratory concentrations shown to induce significant $(\sim 80 \%)$ mortality in this species, and should, by itself, only result in small $(\sim 15 \%)$ population reductions (Relyea and Jones 2009). The formulated product was added to $25 \mathrm{~mL}$ of tank water and then this mixture was distributed across the surface of the mesocosms (Relyea 2012). One hour after the applications, we sampled the middle of the water column and pooled the samples based on herbicide treatment (i.e. present vs. absent; Relyea 2012). The water samples were then refrigerated and later shipped for analysis using high-pressure liquid chromatography (National Testing Laboratories, Ltd., Ypsilanti, MI). In addition, glyphosate treatment tanks were also sampled after termination of the experiment to determine the amount of glyphosate degradation under each UV-B regimen. Finally, water samples from the natal pond were analyzed for glyphosate concentration to increase the amount of field data available. Glyphosate concentration of the $\mathrm{H}+$ treatments at the start of the experiment was $2.75 \mathrm{mg}$ a.e./L and decreased to 0.95 and $0.84 \mathrm{mg}$ a.e./L for $\mathrm{UV}_{\mathrm{M}}$ and $\mathrm{UV}_{\mathrm{L}}$ treatments, respectively, at the end. No glyphosate was detected in the $\mathrm{H}-$ treatments or the natal pond.

\section{Response variables}

For each treatment, we determined salamander survival, mean body size, percentage of metamorphs, and cellular immune response. On 11 June 2013 (day 34), we terminated the experiment by removing all water and leaf litter and recovering all surviving salamanders. This duration was selected because it allowed for approximately 6 weeks 
for larvae to achieve optimum size for metamorphosis (Talentino and Landre 1991; Phillips et al. 2002).

Each recovered individual was measured for snout-vent length (SVL) and weighed to the nearest 0.1 grams. Body size was determined by dividing the mass by SVL. This metric was chosen because it encapsulates an individual's condition by considering mass in a length-specific context (Johnson et al. 2013).

Additionally, survivors were categorized as larvae or metamorphs based on gill morphology at the termination of the experiment; animals with large external gills present were considered larvae and those with reduced or fully absorbed gills were deemed metamorphs. Some statistical analyses were performed independently for larvae and metamorphs (e.g. those involving mass) to account for any effect of metamorphosis on our response variables.

Upon termination of the experiment, we haphazardly selected four larvae and four metamorphs for the immune challenge from each tank. However, only tanks with at least four individuals for either stage were used. Thus, there were at least four replicates per treatment for larvae and at least two replicates for metamorph measurements. Cellular immune response was measured according to Seiter (2011) by administering an injection of phytohemagglutinin (PHA; Sigma Aldrich, St. Louis, MO). PHA causes T-lymphocytes to proliferate rapidly in vivo and in vitro (Smits et al. 1999; Martin et al. 2006). PHA causes measurable swelling at the injection site with greater swelling indicating a stronger T-lymphocyte response and therefore stronger cellular immune response. The PHA assay is a commonly used field method for measuring immune response in various vertebrate taxa (Smits et al. 1999; Martin et al. 2006; Boughton et al. 2011). Gervasi and Foufopoulos (2008) have also demonstrated its usefulness in measuring amphibian immune response.

The immunoassay was prepared by dissolving $2 \mathrm{mg}$ of PHA in $1 \mathrm{~mL}$ of phosphate-buffered saline solution (PBS). Each individual was then injected in the dermis covering the muscle at the base of the tail with $15 \mu \mathrm{L}$ of the PHAsaline solution using a $0.3-\mathrm{mL}$, 32-gauge insulin syringe. Tail thickness measurements of each individual were taken before injection, and 24 and $48 \mathrm{~h}$ post injection (Seiter 2011).

Salamanders were removed from tanks and transported to a nearby field station at the Upper Green River Biological Preserve for the PHA assay. To facilitate handling during injection, we anaesthetized the animals using $0.02 \% \mathrm{MS}-222$ buffered with $\mathrm{NaCO}_{3}$, and before injection, we weighed individuals and measured tail thickness using fine-gauge digital calipers to the nearest $0.01 \mathrm{~mm}$ (Seiter 2011). During the immune challenge, animals were housed individually at the field facility. Immune response was assayed by subtracting the pre-injection tail thickness from the tail thickness at 24 and $48 \mathrm{~h}$ (Seiter 2011). Larvae were anesthetized for all measurements. After measurement, animals were euthanized in a $0.2 \%$ solution of MS222 and preserved in ethanol.

We euthanized all recovered individuals not used for the cellular immune response determination with $0.2 \%$ buffered MS-222, fixed them with $10 \%$ formalin and stored them in $70 \%$ ethanol for assessment of morphological plasticity in response to our treatments. We then obtained a digital image of each larvae using a Nikon D7000 camera and analyzed them for shape using the TPS software suite (Rohlf 2001, 2003, 2013). Lateral tail shapes were determined using 34 landmark coordinates.

\section{Statistical analysis}

The relationship among UV-B, glyphosate, and salamander fitness was evaluated using linear mixed-effects model fitted with restricted maximum likelihood in the lme4 package of $R$ (Bates and Maechler 2009). "Glyphosate" and "UV-B" were fixed categorical variables and "family" and "block" were random effects. Blocks were defined as each row in our experimental design. For all response variables, the magnitude of random effect standard deviation was small, and the between family variation was much less than the between treatment variation. Nevertheless, we did detect random effect variation with respect to salamander family (Fig. S3), so inclusion of random effects removed family-specific variance (such as genetic background, for example) from the experiment-wide error term and improved our ability to detect significant variation due to treatment. As a general strategy for each response variable, we compared a null model that contained only random effects to single-factor models that retained the random effects but also included either herbicide or UV-B treatment level, and then compared two factor models (with and without an interaction term) to the single-factor model with the best support.

We used Akaike's Information Criterion (AIC; Akaike 1973), log-likelihood values, and likelihood ratio tests (LRTs) using the "anova" function in the lme4 package to evaluate the performance of the models (Table 1). LRTs compare the fit of two models, and the probability distribution of the LRT test statistic is approximated by the Chi squared distribution. This strategy is similar to the evaluation of treatment effects through the calculation of the $F$-statistic in a traditional ANOVA. For example, $F$ is calculated as the ratio of the between treatment (in the numerator) and within treatment (in the denominator) variances, where the variance between treatments is attributable to the treatment effects and the variance within treatments is not. Similarly, likelihood ratio tests compare the reduced model (in the numerator) and the alternative model (in the denominator) to determine the variance 
Table 1 Model comparison for survival, body size, number of metamorphs, and swelling after $48 \mathrm{~h}$

\begin{tabular}{|c|c|c|c|c|c|}
\hline & d.f. & $\Delta \mathrm{AIC}$ & $\log$ lik & $X^{2}$ & $\mathrm{P}$ \\
\hline \multicolumn{6}{|l|}{ A. Survival } \\
\hline Null & 3 & 26.6 & -308.92 & - & - \\
\hline Herbicide & 4 & 28.4 & -308.82 & 0.20 & 0.654 \\
\hline UV-B & 4 & $\mathbf{0}$ & -294.91 & 28.03 & $1.20 \mathrm{E}-07$ \\
\hline Herb +UV-B & 5 & 2.44 & -294.84 & 0.13 & 0.716 \\
\hline Herb*UV-B & 6 & 4.12 & -294.68 & 0.46 & 0.796 \\
\hline \multicolumn{6}{|l|}{ B. Body size } \\
\hline Null & 4 & 37.8 & 987.83 & - & - \\
\hline Herbicide & 5 & 35.1 & 990.17 & 4.68 & 0.0304 \\
\hline UV-B & 5 & 31.6 & 991.91 & 8.17 & 0.0043 \\
\hline Herb +UV-B & 6 & 30.6 & 993.42 & 3.01 & 0.0826 \\
\hline Herb*UV-B & 7 & $\mathbf{0}$ & 1009.72 & 35.62 & $1.85 \mathrm{E}-08$ \\
\hline \multicolumn{6}{|l|}{ C. Metamorphs } \\
\hline Null & 3 & 2.64 & -134.77 & - & - \\
\hline Herbicide & 4 & $\mathbf{0}$ & -132.45 & 4.64 & 0.031 \\
\hline UV-B & 4 & 4.29 & -134.59 & 0.35 & 0.552 \\
\hline Herb +UV-B & 5 & 1.19 & -132.04 & 0.81 & 0.368 \\
\hline Herb*UV-B & 6 & 1.47 & -131.2 & 2.53 & 0.282 \\
\hline \multicolumn{6}{|l|}{ D. Swelling ${ }_{\Delta 48}$} \\
\hline Null & 4 & 6.91 & -63.72 & - & - \\
\hline Herbicide & 5 & 8.43 & -63.48 & 0.48 & 0.490 \\
\hline UV-B & 5 & 4.21 & -61.39 & 4.67 & 0.031 \\
\hline Herb +UV-B & 6 & 5.4 & -60.98 & 0.81 & 0.368 \\
\hline Herb*UV-B & 7 & $\mathbf{0}$ & $-\mathbf{5 7 . 2 8}$ & 8.21 & 0.016 \\
\hline
\end{tabular}

Best-fit models are bolded. All models contained clutch and block as random effects

d.f. indicates degrees of freedom, $\triangle A I C$ is the change from lowest AIC value, $\log$ Lik is log likelihood

explained by the addition of the treatment parameter and evaluate the effect of the treatment. Thus, through the evaluation of LRTs using the Chi squared distribution, we can ascertain the importance of our treatment effects in explaining our data. From our perspective, the reason to use LRTs over traditional ANOVA is the ease with which random effects (like family) can be implemented into the analysis to better isolate the effects of our fixed treatments (herbicide and UV-B level).

For survival and number of metamorphs, we modeled individual survival or stage, respectively, as a categorical variable (e.g. alive or dead; larva or metamorph) with a generalized linear mixed-effects model using a logit link and binomial error term. Models were compared as described above. Data were analyzed using a Fisher's exact test with Bonferroni correction to evaluate the specific pattern of treatment effects. For body size and cellular immune response we used a non-parametric randomized residual permutation procedure (RRPP) (Collyer and Adams 2007;
Collyer et al. 2014) to calculate effect sizes between treatment groups and to identify between-group differences. Briefly, this procedure extracted the residuals of a null model and randomly paired them with fitted values. Subsequently, these pseudorandom data were used to calculate pairwise distances using the full model. By repeating this process 10,000 times, we were able to determine the probability of finding differences greater than or equal to the observed $\mathrm{F}$ values for two-model comparisons and the observed distances between group means $\left(\mathrm{D}_{\mathrm{obs}}\right)$ for multiple comparisons. Essentially, this procedure acts like an ANOVA with a multiple comparisons test, but is not constrained by the assumptions associated with a parametric procedure. In cases where the "best" model (as determined above) was not the full model, we performed analyses on both the best model and the full model to evaluate both the most meaningful explanatory variables and our initial hypothesis that there would be an interaction between treatments.

Finally, morphology was analyzed from a covariance matrix of the 34 landmark coordinates after Procrustes superimposition using principal component analysis (PCA), jackknife classification, and RRPP with post hoc multiple comparisons on the points from clutch-independent landmark coordinates. PCA performs a rigid rotation of the data space such that the variation explained by two axes is maximized. By color-coding points in the two-dimensional projection, inferences and trends can be made, but no hypotheses are explicitly tested. The further exploratory technique, jackknife classification, was used to determine how well individuals could be placed into their correct treatment. This classification technique involves removal of one subject, calculation of covariation between variables associated with subject differences within groups, then classifying the removed subject. All 58 available dimensions determined from Eigenanalysis were used for hypothesis testing. Fiftyeight dimensions were used instead of the possible 68 (from 34 coordinates) due to redundancies causing negative eigenvalues for 10 dimensions. The hypothesis that the centroids from each treatment occupied the same position in the morphospace was tested using RRPP with 10,000 iterations and $\mathrm{F}$ as the test statistic. The multiple comparisons test followed the same procedure described above in which pairwise distance matrices were calculated 10,000 times. All analyses were performed using $\mathrm{R}$ version 3.0.2 with the probability of type 1 error $(\alpha)$ equal to 0.05 .

\section{Results}

\section{Survival}

The single-factor model that included UV-B treatment was a better predictor of survival than the model including 
herbicide treatment only, and the two-factor model performed better than the model with UV-B treatment only (Table 1A). This suggests that UV-B level has a greater effect on salamander survival than herbicide presence. Although we did not find model support for a strong interaction between UV-B and herbicide, both $\mathrm{UV}_{\mathrm{M}}$ treatments had significantly more survivors than the $\mathrm{UV}_{\mathrm{L}} / \mathrm{H}+$ treatment $\left(\mathrm{UV}_{\mathrm{M}} / \mathrm{H}+\right.$ Fisher's exact $\mathrm{P}<0.00010 ; \mathrm{UV}_{\mathrm{M}} /$ $\mathrm{H}-$, Fisher's exact $\mathrm{P}=0.00019$ ), but not when compared to the $\mathrm{UV}_{\mathrm{L}} / \mathrm{H}$ - treatment (Table 2). Thus, when herbicide was present, survival was higher in $U_{\mathrm{M}}$ conditions than in $\mathrm{UV}_{\mathrm{L}}$ conditions. However, within a given UV-B level there was no difference in survival due to herbicide presence or absence.

\section{Body size and metamorphs}

In general, body size differences paralleled differences in SVL and mass so we report only results based on body size calculations. Both single-factor models outperformed the null model in explaining the observed variation in body size, but the model with the highest predictive value overall was the two-factor model including the interaction between herbicide and UV (Table 1B). Evaluation of treatment effects using RRPP revealed that $\mathrm{UV}_{\mathrm{L}} / \mathrm{H}-$ had significantly lower body size than all other treatments $\left(\mathrm{D}_{\mathrm{obs}}=0.0045\right.$, $\left.\mathrm{D}_{\text {obs }}=0.0065, \mathrm{D}_{\text {obs }}=0.0073, \mathrm{P}=0.0001\right)$. However, $\mathrm{UV}_{\mathrm{M}} / \mathrm{H}+$ had statistically significantly lower body size than $\mathrm{UV}_{\mathrm{M}} / \mathrm{H}-$ as well $\left(\mathrm{D}_{\text {obs }}=0.0020, \mathrm{P}=0.0450\right)$. In other words, under low UV-B, the presence of herbicide increased body size, and under moderate UV-B, the presence of herbicide decreased body size (Table 2). There was no difference in body size between developmental stages (larva or metamorph) $(\mathrm{F}=0.3233, \mathrm{P}=0.9900)$.

The single-factor model that best predicted the percentage of metamorphs present at the termination of the experiment included the herbicide treatment parameter, and UV level seemed to have no effect when added to herbicide as a two-factor model (Table 1C). Therefore, unlike most other endpoints, the presence or absence of herbicide best explained the percentage of metamorphs among survivors, with $\mathrm{H}+$ treatments having significantly more metamorphs than $\mathrm{H}-$ treatments $(28 \pm 4$ vs. $17 \pm 3 \%$; Fisher's exact $\mathrm{P}=0.04000$ ). Unlike survival where we found significant differences among two-factor treatments even though a single factor was the best predictor, for percentage of metamorphs this was not the case (Table 2).

\section{Cellular immune response}

Cellular immune response was determined by measuring swelling due to T-lymphocyte recruitment following PHA injection. No significant effects of treatments were observed over $24 \mathrm{~h}$ intervals, but significant effects were observed after $48 \mathrm{~h}$ (Table 2). The single factor model that best explained the 48-h swelling data included only the UV treatment parameter, and when herbicide treatment was added to UV level as a two-factor model, the likelihood of the model further improved only when the model included an interaction term (Table 1D). Specifically, when evaluated using RRPP, $\mathrm{UV}_{\mathrm{M}} / \mathrm{H}-$ had a greater change in swelling than $\mathrm{UV}_{\mathrm{M}} / \mathrm{H}+$ and $\mathrm{UV}_{\mathrm{L}} / \mathrm{H}-$ $\left(\mathrm{D}_{\text {obs }}=0.2674, \quad \mathrm{P}=0.017 \quad\right.$ and $\quad \mathrm{D}_{\text {obs }}=0.4098$, $\mathrm{P}=0.0005$, respectively; Table 2). Thus, cellular immune response was lower in $\mathrm{H}+$ treatments compared to the $\mathrm{H}$ - treatment under $\mathrm{UV}_{\mathrm{M}}$ conditions, and it was lower in $\mathrm{UV}_{\mathrm{L}}$ treatments compared to $\mathrm{UV}_{\mathrm{M}}$ treatments in the absence of herbicide.

\section{Morphological plasticity}

The first two principal components (PC) accounted for $58 \%$ of the total variation for the tail morphology (Fig. 2),
Table 2 Summary statistics for various fitness endpoints in this study

\begin{tabular}{|c|c|c|c|c|c|c|c|c|}
\hline \multirow[t]{2}{*}{ Treatment } & \multicolumn{2}{|c|}{ Salamander survival (\%) } & \multicolumn{2}{|c|}{ Body size $\left(\mathrm{g} \mathrm{mm}^{-1}\right)$} & \multicolumn{2}{|c|}{ Metamorphs (\%) } & \multicolumn{2}{|c|}{ Swelling $_{\Delta 48}(\mathrm{~mm})$} \\
\hline & Mean & SEM & Mean & SEM & Mean & SEM & Mean & SEM \\
\hline $\mathrm{UV}_{\mathrm{M}} / \mathrm{H}+$ & $69.17^{\mathrm{a}}$ & 4.23 & $0.0435^{\mathrm{a}}$ & 0.001 & $21.69^{\mathrm{a}}$ & 4.55 & $0.590^{\mathrm{a}}$ & 0.04 \\
\hline $\mathrm{UV}_{\mathrm{M}} / \mathrm{H}-$ & $66.67^{\mathrm{a}}$ & 4.32 & $0.0455^{\mathrm{b}}$ & 0.001 & $16.25^{\mathrm{a}}$ & 4.15 & $0.860^{\mathrm{b}}$ & 0.03 \\
\hline $\mathrm{UV}_{\mathrm{L}} / \mathrm{H}+$ & $39.17^{\mathrm{b}}$ & 4.47 & $0.0463^{\mathrm{a}, \mathrm{b}}$ & 0.002 & $38.83^{\mathrm{a}}$ & 7.17 & $0.670^{\mathrm{a}, \mathrm{b}}$ & 0.06 \\
\hline $\mathrm{UV}_{\mathrm{L}} / \mathrm{H}-$ & $52.50^{\mathrm{a}, \mathrm{b}}$ & 4.57 & $0.0390^{\mathrm{c}}$ & 0.001 & $17.46^{\mathrm{a}}$ & 4.82 & $0.440^{\mathrm{a}}$ & 0.03 \\
\hline
\end{tabular}

Different letters indicate significant differences according to RRPP or Fisher's exact test (see Methods) with $\alpha=0.05$. $\mathrm{UV}_{\mathrm{L}} / \mathrm{H}+$ had significantly lower survival than both of the $\mathrm{UV}_{\mathrm{M}}$ treatments. Body size in the $\mathrm{UV}_{\mathrm{L}} / \mathrm{H}-$ treatment was significantly lower than all other treatments and body size in $\mathrm{UV}_{\mathrm{M}} / \mathrm{H}+$ was significantly lower than $\mathrm{UV}_{\mathrm{M}} / \mathrm{H}-$. There were no differences in percent of survivors that were metamorphs among treatments. Swelling after $48 \mathrm{~h}$ (i.e. cellular immune response) in the $\mathrm{UV}_{\mathrm{M}} / \mathrm{H}-$ treatment was significantly higher than the $\mathrm{UV}_{\mathrm{M}} / \mathrm{H}+$ treatment and $\mathrm{UV}_{\mathrm{L}} / \mathrm{H}-$ treatment

$S E M$ standard error of the mean 


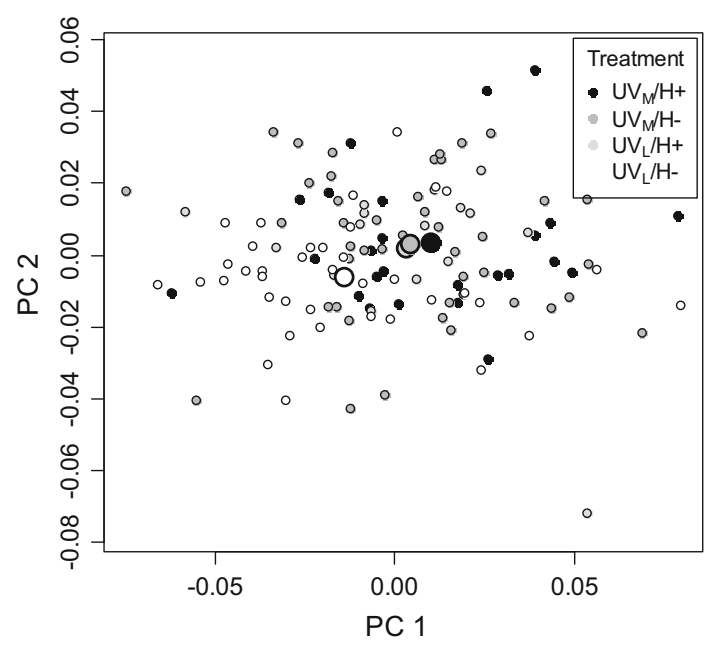

Fig. 2 Clutch independent principal component ordination plots for tail morphology of spotted salamander (Ambystoma maculatum) larvae based on covariance matrices. PC1 and PC2 explain 58\% of the variation in eigenvalues. In addition, there was a 0.91 correlation between this two dimensional projections and the full data space. The large dots denote the centroid of each treatment

with the third and fourth PCs contributing another $21 \%$. This suggests that there is substantial variation not shown in the two-dimensional ordination. However, the two-dimensional projection and the full data space were highly correlated $(\mathrm{R}=0.91)$. The $\mathrm{UV}_{\mathrm{M}}$ treatments tended to have higher PC2 values than the $\mathrm{UV}_{\mathrm{L}}$ treatments, but no obviously distinct clusters were observed.

The jackknife classification yielded $47 \%$ accuracy in placing individuals into the correct treatment. The majority of misclassifications had at least one of the factors (i.e. UV-B or herbicide) classified correctly (Table 3). When classification was run for each factor individually, the success was 58 and $66 \%$ for UV-B and herbicide, respectively (Table S3). Expected correct classification by chance for treatment and single factors was 25 and $50 \%$, respectively. Therefore, our individuals were placed into the correct group more often than would occur at random and treatment was a good discriminator among individuals.

Finally, RRPP revealed that there were significant differences (Table 4) in centroid location in the morphospace for $\mathrm{UV}_{\mathrm{L}} / \mathrm{H}-$ and all other treatments (Fig. 2). The major difference between $\mathrm{UV}_{\mathrm{L}} / \mathrm{H}-$ animals was in tail arch, but the tail muscle also tended to be shorter and narrower in these larvae compared to the other treatments (Fig. S4). Under $\mathrm{UV}_{\mathrm{M}}$ conditions, morphology did not change with herbicide addition, but the presence of herbicide in the $\mathrm{UV}_{\mathrm{L}}$ treatment (i.e. $\mathrm{UV}_{\mathrm{L}} / \mathrm{H}+$ ) influenced the morphology to converge on that of the moderate UV-B treatments.
Table 3 Jackknife (leave one out cross-validation) classification table for individuals based on tail morphology

\begin{tabular}{lcccc}
\hline & $\mathrm{UV}_{\mathrm{M}} / \mathrm{H}+$ & $\mathrm{UV}_{\mathrm{M}} / \mathrm{H}-$ & $\mathrm{UV}_{\mathrm{L}} / \mathrm{H}+$ & $\mathrm{UV}_{\mathrm{L}} / \mathrm{H}-$ \\
\hline $\mathrm{UV}_{\mathrm{M}} / \mathrm{H}+$ & $\mathbf{9}$ & 9 & 4 & 4 \\
$\mathrm{UV}_{\mathrm{M}} / \mathrm{H}-$ & 11 & $\mathbf{2 1}$ & 4 & 9 \\
$\mathrm{UV}_{\mathrm{L}} / \mathrm{H}+$ & 4 & 3 & $\mathbf{1 0}$ & 0 \\
$\mathrm{UV}_{\mathrm{L}} / \mathrm{H}-$ & 4 & 10 & 0 & $\mathbf{1 9}$ \\
\hline
\end{tabular}

Posterior probabilities were used to determine into which treatment an individual was classified. Rows represent actual treatments and columns are the treatment into which an individual was placed. For example, $11 \mathrm{UV}_{\mathrm{M}} / \mathrm{H}$ - individuals were incorrectly placed into the $\mathrm{UV}_{\mathrm{M}} / \mathrm{H}+$ treatment. Forty-seven percent of individuals (bold values) were classified correctly

Table $4 \mathrm{P}$ values for pairwise distances among treatments for centroid location in the 58 dimensional morphospace

\begin{tabular}{llll}
\hline Treatment & $\mathrm{UV}_{\mathrm{M}} / \mathrm{H}+$ & $\mathrm{UV}_{\mathrm{M}} / \mathrm{H}-$ & $\mathrm{UV}_{\mathrm{L}} / \mathrm{H}+$ \\
\hline $\mathrm{UV}_{\mathrm{M}} / \mathrm{H}-$ & 0.2685 & - & - \\
$\mathrm{UV}_{\mathrm{L}} / \mathrm{H}+$ & 0.1883 & 0.0738 & - \\
$\mathrm{UV}_{\mathrm{L}} / \mathrm{H}-$ & $\mathbf{0 . 0 0 1 0}$ & $\mathbf{0 . 0 0 2 1}$ & $\mathbf{0 . 0 0 1 3}$
\end{tabular}

Bold values are significant with $\alpha=0.05$

\section{Discussion}

This study aimed to understand how glyphosate-based herbicide affects salamanders under different UV-B conditions. We found evidence to suggest that effects vary based on herbicide exposure and UV-B level. In the presence of glyphosate-based herbicide, UV-B conditions significantly affected the survival of larval salamanders. In addition, UV-B appeared to improve survival, body size, and cellular immune response. Finally, the interaction between UV-B level and exposure to herbicide can have significant effects on salamander body size and tail morphology.

\section{Survival}

To our knowledge, all semi-natural and natural studies with glyphosate-based herbicides have had ambient UV-B conditions that are reflective of our $\mathrm{UV}_{\mathrm{M}}$ condition (e.g. Relyea 2012). Recent studies using natural ponds have found glyphosate-based herbicide to have little effect on amphibians (Edge et al. 2012, 2013). Consistent with these recent field studies, we found little effect of herbicide on survival. However, with respect to the main effects in our study, we found a strong positive effect of UV-B level. These results were unexpected because several mesocosm 
studies have found that glyphosate-based herbicides both harm amphibians and alter aquatic systems (Howe et al. 2004; Relyea 2005c; Relyea et al. 2005), and that greater UV-B exposure, typically higher than in our study, can have negative consequences on amphibians (e.g. Tevini 1993; Broomhall et al. 2000; Tietge et al. 2001; Blaustein et al. 2003; Bancroft et al. 2008a).

Our data indicate that larval salamanders are positively affected by a moderate increase in UV-B exposure. $U_{\mathrm{L}}$ survival was significantly lower than $U_{\mathrm{M}}$ survival, which suggests that $U_{\mathrm{M}}$ conditions were optimal in this study. A previous study by Bridges and Boone (2003) found that a "high" subsurface UV-B level $\left(46 \mu \mathrm{W} / \mathrm{cm}^{2}\right)$ improved survival of Southern leopard frog (Lithobates sphenocephalus) tadpoles compared to medium $\left(27.4 \mu \mathrm{W} / \mathrm{cm}^{2}\right)$ and low $\left(0.54 \mu \mathrm{W} / \mathrm{cm}^{2}\right)$ subsurface UV-B levels. These UV-B values are similar to those of our study $\left(\mathrm{UV}_{\mathrm{M}}\right.$ : $51 \mu \mathrm{W} / \mathrm{cm}^{2}$; $\mathrm{UV}_{\mathrm{L}}: 12 \mu \mathrm{W} / \mathrm{cm}^{2}$ ) and produced similar results. Bridges and Boone (2003) attributed their outcome to the possibility of their filters eliminating a range of wavelengths (such as UV-A) that are critical for vital functions, such as vitamin D production in humans, but the specific mechanism remains unknown.

Within a given UV-B regime, addition of herbicide did not reduce survival, but when herbicide was present, RRPP revealed that $U_{M}$ ponds had greater survival than $U V_{L}$ ponds. We propose two plausible mechanisms that appear consistent with our observations of a possible interaction between UV-B and the glyphosate-based herbicide. These speculations could be investigated with further research: UV-induced breakdown of herbicide components or trophic interactions (Lund-Høie and Friestad 1986; Zaga et al. 1998; Williamson 1995; Hader et al. 2007, 2011).

$\mathrm{UV}$-induced breakdown of chemical compounds is a common feature of herbicide mixtures (Lund-Høie and Friestad 1986; Zaga et al. 1998). In our study, the active ingredient glyphosate broke down at similar rates in both UV-B conditions. Despite several studies showing that POEA is significantly more toxic than glyphosate itself (Mann and Bidwell 2001; Tsui and Chu 2003; Howe et al. 2004; Brausch et al. 2007; Relyea and Jones 2009), little is known about the breakdown of the surfactant in natural systems. Consistent with other studies (Relyea 2012; Edge et al. 2013) the breakdown of the surfactant, POEA, and other inactive ingredients was not measured. However, it is possible that POEA (or some other potentially damaging inactive ingredient) breaks down more readily under higher UV-B levels and this could account for the observed differences in survival when herbicide was present. The predicted half-life for POEA in water is 21-42 days, which is three times longer than estimates for glyphosate (Giesy et al. 2000). Therefore, although glyphosate concentrations dropped approximately three-fold during the study period,
POEA concentrations may have remained higher unless it was degraded by UV-B. Sediment significantly reduces the toxicity and concentration of POEA in microcosms (Wang et al. 2005). No soil was used in our study, but leaf litter and periphyton may have removed the surfactant from the water column (Giesy et al. 2000). Exclusion of sediment could have prevented sequestration of POEA and reduced the turbidity in our tanks, thereby potentially increasing the duration of high concentrations of herbicide and/or increasing the penetration of UV-B. If this is the case, in natural systems with sediment, UV-induced breakdown may not be relevant. However, because higher UV-B levels can lead to increased periphyton growth (Scheessele 2007; but see Vinebrooke and Leavitt 1996), there may have been greater removal of the surfactant or other ingredients from the water column in the $\mathrm{UV}_{\mathrm{M}}$ treatment. In any case, future studies using these herbicides should focus on surfactant concentrations and breakdown instead of the active ingredient.

Alternatively, since the only food source for salamanders in this study was zooplankton, any effect the treatments had on zooplankton communities could potentially have a strong direct trophic effect on the salamanders (Scheessele 2007). In our study, the zooplankton may have moved deeper in the water column in the $\mathrm{UV}_{\mathrm{M}}$ treatments compared to the $\mathrm{UV}_{\mathrm{L}}$ treatments. Zooplankton move deeper in the water column, up to $50 \mathrm{~cm}$, when exposed to UV-B radiation (Storz and Paul 1998; Speekmann et al. 2000; Rhode et al. 2001) and larval salamanders have the tendency to remain in deeper, cooler waters (Bancroft et al. $2008 b)$. Therefore, in the $U_{\mathrm{M}}$ treatments, food was potentially more abundant in the deep water salamanders prefer. Conversely, in the $\mathrm{UV}_{\mathrm{L}}$ treatments, salamanders would forage higher in the water column, which normally might not affect salamander survival, but since the water surface was warmer than the bottom (Table S1) and the films reduced the ability of the water to mix, the herbicide should have stratified and been more concentrated at the water's surface (Jones et al. 2010). Glyphosate-based herbicide can have a greater lethal effect on larval amphibians than on zooplankton communities (Relyea 2005c). Thus, exposure to greater concentrations of herbicide near the surface due to pursuit of prey items, could possibly account for the differential survival between UV-B levels.

\section{Body size and metamorphosis}

In the absence of herbicide, animals in the $\mathrm{UV}_{\mathrm{M}}$ treatment had greater body size than animals in the $U_{\mathrm{L}}$ treatment. These differences in body size could potentially have strong long-term consequences because body size has a significant effect on several life history traits of ectotherms. We anticipated that body size would be reduced with the 
addition of herbicide under both UV-B treatments because of stress-induced growth reduction (Denver 2009). As expected, body size decreased with addition of herbicide in the $\mathrm{UV}_{\mathrm{M}}$ treatment. However, body size increased with the addition of herbicide in the $\mathrm{UV}_{\mathrm{L}}$ treatment. Size has been affected by glyphosate-based herbicide in other taxa; goldstriped salamander (Chioglossa lusitanica) embryos exposed to Roundup Plus ${ }^{\circledR}$ were significantly longer at hatching than controls (Ortiz-Santaliestra et al. 2011). This interaction between herbicide and UV-B was surprising and the exact mechanism is unknown, but we hypothesize that it involves significant indirect effects of plankton communities on larval competition under different UV and herbicide conditions.

Timing of metamorphosis is a phenotypically plastic trait that is, at least in part, controlled by environmental conditions, and typically, it is the largest (i.e. best condition) individuals that leave first when salamanders metamorphose to escape a stressful environment (e.g. herbicide present) (Whiteman et al. 2012). The salamanders in our study achieved the "optimum" size for metamorphosis for this species (Phillips et al. 2002), but the majority of individuals did not metamorphose. Interestingly, the proportion of metamorphs present in a tank was affected by herbicide level according to our model selection process. There was a greater proportion of metamorphs when herbicide was present, which suggests that the $\mathrm{H}+$ environment was more stressful than the $\mathrm{H}$ - environment even if survival and body size were unaffected. Alternatively, the herbicide may induce metamorphosis, for example, by affecting the hormonal control of the metamorphosis genetic pathways (Hayes et al. 2002; El-Shebly and El-kady 2008; Lanctôt et al. 2013; Romano et al. 2012).

\section{Cellular immune response}

The immunological benefits of UV-B exposure are equivocal. We found that the combined $\mathrm{UV}_{\mathrm{L}}$ treatments resulted in a weaker cellular immune response than the combined $\mathrm{UV}_{\mathrm{M}}$ treatments. Since $\mathrm{UV}_{\mathrm{M}}$ conditions can be considered optimal (see above), then it is not surprising that suboptimal conditions weakened the cellular immune response. It is possible this difference may be related to vitamin D production as Bridges and Boone (2003) suggest. Vitamin D receptors are present in many immune cells (e.g. T cells, B cells, monocytes, and antigen-presenting cells), vitamin D supplementation has beneficial effects in autoimmunity, and vitamin $\mathrm{D}$ is important for the regulation of inflammatory responses (Prietl et al. 2013). Since exposure to UV-B stimulates vitamin D production, animals in the $\mathrm{UV}_{\mathrm{L}}$ treatments may have been immunodeficient relative to $\mathrm{UV}_{\mathrm{M}}$ treatment animals. We expected the herbicide to produce a stress-induced (i.e. corticosterone-induced) immunosuppression (e.g. Gisler 1974), and this was the case for our measured cellular immune response in the moderate UV-B treatments.

\section{Morphology changes}

Individuals were placed into the correct treatment more often than expected by chance, and the majority of misclassifications had at least one of the factors (UV or herbicide) correct (Table 3). Therefore, our treatments were distinct enough from each other for correct classification even though the morphology in three treatments did not differ in morphospace. The morphology of the $\mathrm{UV}_{\mathrm{L}} / \mathrm{H}+$ salamanders converged on that of the two $\mathrm{UV}_{\mathrm{M}}$ treatments. In contrast, the $\mathrm{UV}_{\mathrm{L}} / \mathrm{H}$ - larvae had tails with a greater downward bend and shorter tail muscles than the other three treatments (Fig. S4).We hypothesize that this phenotypic variation may be the result of malnutrition (Jung et al. 1978), an interaction between food availability and treatment, or hormonal disruption because the $\mathrm{UV}_{\mathrm{L}} / \mathrm{H}-$ larvae also had the lowest body condition (Table 2). The presence of glyphosate-based herbicide may counteract this stress-induced phenotype, preventing the deformity in $\mathrm{UV}_{\mathrm{L}} / \mathrm{H}+$ larvae. Alternatively, the observed downward, concave tail bend could have been induced to generate greater upward lift (Wilga and Lauder 2001), while conserving energy (Takagi et al. 2013), to facilitate feeding on zooplankton higher in the water column consistent with the trophic scenario we describe for survival. Under the $\mathrm{UV}_{\mathrm{L}}$ condition, the presence of glyphosate-based herbicide may have prevented the induction of this tail phenotype for obtaining food near the water's surface.

Relyea (2012) found that a glyphosate-based herbicide, Roundup Original $\mathrm{MAX}^{\circledR}$, could induce a morphological response typically generated by predators in leopard frog (Lithobates pipiens) and wood frog (Lithobates sylvaticus) tadpoles. Presumably, such induced phenotypes should be maladaptive in the absence of predators. Alton et al. (2010) found that sub-ambient UV-B levels (i.e. $\sim 38 \mu \mathrm{W} / \mathrm{cm}^{2}$ ) inhibited predator-induced morphology. Our study is the first to suggest that the presence of glyphosate-based herbicide can result in tail morphology changes in a salamander species under $\mathrm{UV}_{\mathrm{L}}$ conditions. Under moderate UV-B levels, there was no difference in morphology between herbicide present and absent groups. The reduction in body size, but not the observed change tail morphology corresponds to known responses of A. maculatum to predators (Urban 2008, 2010), therefore we may be observing a response that is distinct from the anuran examples above. The underlying mechanism of herbicide-induced morphology remains unclear. However, the present hypothesis is that interference with stress hormones involved with antipredator defenses causes this maladaptive plasticity (Glennemeier and Denver 2002; Relyea 2012). 


\section{Conclusions}

Amphibians have demonstrated the ability to locally adapt to UV-B and pesticide use (Marquis et al. 2009; Hua et al. 2013b), to develop cross-tolerance to pesticides with a common mode of action (Hua et al. 2013a), and to hormetically respond to sublethal exposure to pesticides (Hua et al. 2013b). Our study has demonstrated that UV-B may mitigate some effects of glyphosate-based herbicide exposure and that UV levels moderately exceeding those typical of closed canopy ponds can confer immunological benefits. Additionally, field studies with natural ponds have found that glyphosate-based herbicide alone results in low mortality and that dissolved organic carbon reduces the penetration of UV radiation below the water's surface (Crump et al. 1999b, b; Palen et al. 2002; Edge et al. 2012, 2013). Therefore, although these stressors have the potential to considerably affect amphibians, their danger can be mitigated by certain environmental conditions.

Amphibians in open ponds, particularly near agricultural fields, are more likely to be exposed to glyphosate-based herbicides than those in forested ponds. Agricultural use of these herbicides is $\sim 23$-fold higher than non-agricultural (e.g. silvicultural) use (Grube et al. 2011) and agricultural activity generally occurs in large open areas with plenty of sunlight. Habitat modifications can decrease the amount of available forested ponds and drive amphibians to open ponds that are more likely to be exposed to herbicide (e.g. via drift). Although ponds nearer to open canopy habitat may have a higher risk of herbicide exposure, the results of our present study suggest that moderately elevated levels of UV-B could potentially mitigate deleterious effects on salamander survival should they be exposed to herbicide. Conversely, while closed canopy ponds have a lower risk of exposure, individuals in these ponds may be more likely to perish in the lower UV-B conditions. The UV-B levels used in this study were conservative estimates of these alternative habitat types and therefore are representative of the possible fitness consequences herbicide exposure can have on larval salamanders. When considering the anthropogenic causes of amphibian population declines, interactions among stressors need to be addressed, because the outcomes may be unexpected.

Acknowledgments We would like to thank J. Floyd, A. Levis, D. Stinson, A. Esterle, and K. Ziegler for their valuable assistance in animal collection, mesocosm preparation and maintenance, and various other tasks during the experiment. Additionally, we would like to thank A. Meier, M. Collyer, M. Boone, and three anonymous reviewers for critically reading this manuscript. We are grateful to $\mathrm{M}$. Collyer for his invaluable assistance with statistical analysis and $\mathrm{R}$ coding. Finally, this work was supported by the Kentucky Academy of Science Marcia Athey Research Grant (NAL), Western Kentucky University Graduate Research Grant (NAL), Western Kentucky
RCAP grant (JRJ), and the Western Kentucky University Biodiversity Center and Green River Preserve.

Conflict of interest The authors declare that they have no conflict of interest.

Ethical standards All field protocols were conducted under necessary permits acquired from state and federal authorities listed above.

\section{References}

Akaike H (1973) Information theory and an extension of the maximum likelihood principle. In: Proceedings of Second International Symposium on Information Theory. Budapest: Akademiai Kiado, pp. 267-281

Alton LA, Wilson RS, Franklin CE (2010) Risk of predation enhances the lethal effects of UV-B in amphibians. Glob Change Biol 16:538-545

Bancroft BA, Baker NJ, Blaustein AR (2008a) A meta-analysis of the effects of ultraviolet $B$ radiation and its synergistic interactions with $\mathrm{pH}$, contaminants, and disease on amphibian survival. Conserv Biol 22:987-996

Bancroft BA, Baker NJ, Searle CL et al (2008b) Larval amphibians seek warm temperatures and do not avoid harmful UVB radiation. Behav Ecol 19:879-886

Barolo D (1993) Reregistration eligibility decision for glyphosate

Bates D, Maechler M (2009) Package "lme4." URL http://lme4.rforge.r-project.org/

Baylis AD (2000) Why glyphosate is a global herbicide: strengths, weaknesses and prospects. Pest Manag Sci 56:299-308

Bernal MH, Solomon KR, Carrasquilla G (2009) Toxicity of formulated glyphosate (Glyphos) and Cosmo-Flux to larval and juvenile Colombian frogs 2. Field and laboratory microcosm acute toxicity. J Toxicol Environ Health A 72:966-973

Blaustein AR, Hoffman PD, Hokit DG et al (1994) UV repair and resistance to solar UV-B in amphibian eggs: a link to population declines? Proc Natl Acad Sci 91:1791-1795

Blaustein AR, Romansic JM, Kiesecker JM, Hatch AC (2003) Ultraviolet radiation, toxic chemicals and amphibian population declines. Divers Distrib 9:123-140

Blaustein AR, Gervasi SS, Johnson PTJ et al (2012) Ecophysiology meets conservation: understanding the role of disease in amphibian population declines. Philos Trans R Soc B Biol Sci 367:1688-1707

Boughton RK, Joop G, Armitage SAO (2011) Outdoor immunology: methodological considerations for ecologists. Funct Ecol 25:81-100

Bradford DF, Knapp RA, Sparling DW et al (2011) Pesticide distributions and population declines of California, USA, alpine frogs, Rana muscosa and Rana sierrae. Environ Toxicol Chem 30:682-691

Brausch JM, Beall B, Smith PN (2007) Acute and sub-lethal toxicity of three POEA surfactant formulations to Daphnia magna. Bull Environ Contam Toxicol 78:510-514

Bridges CM, Boone MD (2003) The interactive effects of UV-B and insecticide exposure on tadpole survival, growth and development. Biol Conserv 113:49-54

Bridges CM, Semlitsch RD (2001) Genetic variation in insecticide tolerance in a population of southern leopard frogs (Rana sphenocephala): implications for amphibian conservation. Copeia 2001:7-13 
Broomhall SD, Osborne WS, Cunningham RB (2000) Comparative effects of ambient ultraviolet-B radiation on two sympatric species of Australian frogs. Conserv Biol 14:420-427

Chen CY, Hathaway KM, Folt CL (2004) Multiple stress effects of Vision ${ }^{\circledR}$ herbicide, $\mathrm{pH}$, and food on zooplankton and larval amphibian species from forest wetlands. Environ Toxicol Chem $23: 823-831$

Cockell CS, Blaustein AR (2000) "Ultraviolet spring" and the ecological consequences of catastrophic impacts. Ecol Lett 3:77-81

Collyer ML, Adams DC (2007) Analysis of two-state multivariate phenotypic change in ecological studies. Ecology 88:683-692

Collyer ML, Sekora DJ, Adams DC (2014) A method for analysis of phenotypic change for phenotypes described by high-dimensional data. Heredity. doi:10.1038/hdy.2014.75

Cordero RR, Seckmeyer G, Damiani A et al (2013) The world's highest levels of surface UV. Photochem Photobiol Sci 13(1):70-81

Croteau MC, Davidson MA, Lean DRS, Trudeau VL (2008) Global increases in ultraviolet B radiation: potential impacts on amphibian development and metamorphosis. Physiol Biochem Zool PBZ 81:743-761

Crump D, Berrill M, Coulson D et al (1999a) Sensitivity of amphibian embryos, tadpoles, and larvae to enhanced UV-B radiation in natural pond conditions. Can J Zool 77:1956-1966

Crump D, Lean D, Berrill M et al (1999b) Spectral irradiance in pond water: influence of water chemistry. Photochem Photobiol 70:893-901

Davidson C (2004) Declining downwind: amphibian population declines in California and historical pesticide use. Ecol Appl 14:1892-1902

Davidson C, Knapp RA (2007) Multiple stressors and amphibian declines: dual impacts of pesticides and fish on yellow-legged frogs. Ecol Appl 17:587-597

Denver RJ (2009) Stress hormones mediate environment-genotype interactions during amphibian development. Gen Comp Endocrinol 164:20-31

Edge CB, Thompson DG, Hao C, Houlahan JE (2012) A silviculture application of the glyphosate-based herbicide VisionMAX to wetlands has limited direct effects on amphibian larvae. Environ Toxicol Chem 31:2375-2383

Edge CB, Gahl MK, Thompson DG, Houlahan JE (2013) Laboratory and field exposure of two species of juvenile amphibians to a glyphosate-based herbicide and Batrachochytrium dendrobatidis. Sci Total Environ 444:145-152

Edginton AN, Sheridan PM, Stephenson GR et al (2004) Comparative effects of $\mathrm{pH}$ and Vision ${ }^{\circledR}$ herbicide on two life stages of four anuran amphibian species. Environ Toxicol Chem 23:815-822

Edwards WM, Triplett GB, Kramer RM (1980) A watershed study of glyphosate transport in runoff. J Environ Qual 9:661

Egea-Serrano A, Relyea RA, Tejedo M, Torralva M (2012) Understanding of the impact of chemicals on amphibians: a metaanalytic review. Ecol Evol 2:1382-1397

El-Shebly AA, El-kady MAH (2008) Effects of glyphosate herbicide on serum growth hormone $(\mathrm{GH})$ levels and muscle protein content in Nile tilapia (Oreochromis niloticus L.). Res J Fish Hydrobiol 3:84-88

Flint SD, Caldwell MM (1998) Solar UV-B and visible radiation in tropical forest gaps: measurements partitioning direct and diffuse radiation. Glob Change Biol 4:863-870

Gallant AL, Klaver RW, Casper GS, Lannoo MJ (2007) Global rates of habitat loss and implications for amphibian conservation. Copeia 2007:967-979

Gervasi SS, Foufopoulos J (2008) Costs of plasticity: responses to desiccation decrease post-metamorphic immune function in a pond-breeding amphibian. Funct Ecol 22:100-108
Giesy JP, Dobson S, Solomon KR (2000) Ecotoxicological risk assessment for Roundup herbicide. Rev Env Contam Toxicol 167:35-120

Gilbert SF, Epel D (2009) Ecological developmental biology: integrating epigenetics, medicine, and evolution. Sinauer Associates, Sunderland

Gisler R (1974) Stress and the hormonal regulation of the immune response in mice. Psychother Psychosom 23:197-208

Glennemeier KA, Denver RJ (2002) Small changes in whole-body corticosterone content affect larval Rana pipiens fitness components. Gen Comp Endocrinol 127:16-25

Govindarajulu PP (2008) Literature review of impacts of glyphosate herbicide on amphibians: What risks can silvicultural use of this herbicide pose for amphibians in BC? Victoria: BC Ministry of Environment

Grube A, Donaldson D, Kiely T, Wu L (2011) Pesticides industry sales and usage: 2006 and 2007 market estimates

Hader D-P, Kumar HD, Smith RC, Worrest RC (2007) Effects of solar UV radiation on aquatic ecosystems and interactions with climate change. Photochem Photobiol Sci 6:267-285

Hader D-P, Helbling EW, Williamson CE, Worrest RC (2011) Effects of UV radiation on aquatic ecosystems and interactions with climate change. Photochem Photobiol Sci 10:242-260

Hayes TB, Collins A, Lee M et al (2002) Hermaphroditic, demasculinized frogs after exposure to the herbicide atrazine at low ecologically relevant doses. Proc Natl Acad Sci 99:5476-5480

Herman JR, Bhartia PK, Ziemke J et al (1996) UV-B increases (1979-1992) from decreases in total ozone. Geophys Res Lett 23:2117-2120

Houlahan JE, Findlay CS, Schmidt BR et al (2000) Quantitative evidence for global amphibian population declines. Nature 404:752-755

Howe CM, Berrill M, Pauli BD et al (2004) Toxicity of glyphosatebased pesticides to four North American frog species. Environ Toxicol Chem 23:1928-1938

Hua J, Cothran R, Stoler A, Relyea R (2013a) Cross-tolerance in amphibians: wood frog mortality when exposed to three insecticides with a common mode of action. Environ Toxicol Chem 32:932-936

Hua J, Morehouse NI, Relyea R (2013b) Pesticide tolerance in amphibians: induced tolerance in susceptible populations, constitutive tolerance in tolerant populations. Evol Appl 6:1028-1040

Johnson JR, Ryan ME, Micheletti SJ, Shaffer HB (2013) Short pond hydroperiod decreases fitness of nonnative hybrid salamanders. Anim Conserv 16:556-565

Jones DK, Hammond JI, Relyea RA (2010) Roundup ${ }^{\circledR}$ and amphibians: the importance of concentration, application time, and stratification. Environ Toxicol Chem 29:2016-2025

Jones DK, Hammond JI, Relyea RA (2011) Competitive stress can make the herbicide Roundup ${ }^{\circledR}$ more deadly to larval amphibians. Environ Toxicol Chem 30:446-454

Jung RT, Davie M, Hunter JO, Chalmers TM (1978) Ultraviolet light: an effective treatment of osteomalacia in malabsorption. Br Med J 1:1668-1669

Kerby JL, Hart AJ, Storfer A (2011) Combined effects of virus, pesticide, and predator cue on the larval tiger salamander (Ambystoma tigrinum). EcoHealth 8:46-54

Kerr JB, McElroy CT (1993) Evidence for large upward trends of ultraviolet-B radiation linked to ozone depletion. Science 262:1032-1034

Kiesecker JM (2011) Global stressors and the global decline of amphibians: tipping the stress immunocompetency axis. Ecol Res 26:897-908

Krasny ME, Whitmore MC (1992) Gradual and sudden forest canopy gaps in Allegheny northern hardwood forests. Can J For Res 22:139-143 
Lanctôt C, Robertson C, Navarro-Martín L et al (2013) Effects of the glyphosate-based herbicide Roundup WeatherMax ${ }^{\circledR}$ on metamorphosis of wood frogs (Lithobates sylvaticus) in natural wetlands. Aquat Toxicol 140-141:48-57

Lund-Høie K, Friestad HO (1986) Photodegradation of the herbicide glyphosate in water. Bull Environ Contam Toxicol 36:723-729

Mann RM, Bidwell JR (2001) The acute toxicity of agricultural surfactants to the tadpoles of four Australian and two exotic frogs. Environ Pollut 114:195-205

Marquis O, Miaud C, Ficetola GF et al (2009) Variation in genotoxic stress tolerance among frog populations exposed to UV and pollutant gradients. Aquat Toxicol 95:152-161

Martin LB, Han P, Lewittes J et al (2006) Phytohemagglutinininduced skin swelling in birds: histological support for a classic immunoecological technique. Funct Ecol 20:290-299

Middleton EM, Herman JR, Celarier EA et al (2001) Evaluating ultraviolet radiation exposure with satellite data at sites of amphibian declines in Central and South America. Conserv Biol 15:914-929

Ortiz-Santaliestra ME, Fernández-Benéitez MJ, Lizana M, Marco A (2011) Influence of a combination of agricultural chemicals on embryos of the endangered gold-striped salamander (Chioglossa lusitanica). Arch Environ Contam Toxicol 60:672-680

Palen WJ, Schindler DE, Adams MJ et al (2002) Optical characteristics of natural waters protect amphibians from UV-B in the U.S. pacific northwest. Ecology 83:2951-2957

Petranka JW (1998) Salamanders of the United States and Canada. Smithsonian Institution Press, Washington

Phillips CA, Johnson JR, Dreslik MJ, Petzing JE (2002) Effects of hydroperiod on recruitment of mole salamanders (Genus Ambystoma) at a temporary pond in Vermilion County, Illinois. Trans Ill State Acad Sci 95:131-139

Prietl B, Treiber G, Pieber TR, Amrein K (2013) Vitamin D and immune function. Nutrients 5:2502-2521

Puglis HJ, Boone MD (2011) Effects of technical-grade active ingredient vs. commercial formulation of seven pesticides in the presence or absence of UV radiation on survival of green frog tadpoles. Arch Environ Contam Toxicol 60:145-155

Relyea RA (2003) Predators come and predators go: the reversibility of predator-induced traits. Ecology 84:1840-1848

Relyea RA (2004) Fine-tuned phenotypes: tadpole plasticity under 16 combinations of predators and competitors. Ecology 85:172-179

Relyea RA (2005a) The lethal impacts of Roundup and predatory stress on six species of North American tadpoles. Arch Environ Contam Toxicol 48:351-357. doi:10.1007/s00244-004-0086-0

Relyea RA (2005b) The lethal impact of Roundup on aquatic and terrestrial amphibians. Ecol Appl 15:1118-1124

Relyea RA (2005c) The impact of insecticides and herbicides on the biodiversity and productivity of aquatic communities. Ecol Appl 15:618-627

Relyea RA (2006) The effects of pesticides, pH, and predatory stress on amphibians under mesocosm conditions. Ecotoxicology 15:503-511

Relyea RA (2012) New effects of roundup on amphibians: predators reduce herbicide mortality; herbicides induce antipredator morphology. Ecol Appl 22:634-647

Relyea RA, Hoverman JT (2008) Interactive effects of predators and a pesticide on aquatic communities. Oikos 117:1647-1658

Relyea RA, Jones DK (2009) The toxicity of Roundup Original Max ${ }^{\circledR}$ to 13 species of larval amphibians. Environ Toxicol Chem 28:2004-2008

Relyea RA, Schoeppner NM, Hoverman JT (2005) Pesticides and amphibians: the importance of community context. Ecol Appl 15:1125-1134

Rhode SC, Pawlowski M, Tollrian R (2001) The impact of ultraviolet radiation on the vertical distribution of zooplankton of the genus Daphnia. Nature 412:69-72
Rohlf FJ (2001) TPSSDIG, Version 1.31. Department of Ecology and Evolution, State University of New York at Stony Brook, Stony Brook, New York, USA

Rohlf FJ (2003) TPSRELW, Version 1.29. Department of Ecology and Evolution, State University of New York at Stony Brook, Stony Brook, New York, USA

Rohlf FJ (2013) TPSUTIL, Version 1.58. Department of Ecology and Evolution, State University of New York at Stony Brook, Stony Brook, New York, USA

Romano MA, Romano RM, Santos LD et al (2012) Glyphosate impairs male offspring reproductive development by disrupting gonadotropin expression. Arch Toxicol 86:663-673

Scheessele EA (2007) Indirect effects of ultraviolet-B radiation on larval amphibians as mediated by food quality and trophic interactions. Dissertation, Oregon State University

Seiter S (2011) Predator presence suppresses immune function in a larval amphibian. Evol Ecol Res 13:283-293

Shayeghi M, Dehghani MH, Alimohammadi M, Goodini K (2012) Using ultraviolet irradiation for removal of Malathion pesticide in water. J Arthropod-Borne Dis 6:45

Smits JE, Bortolotti GR, Tella JL (1999) Simplifying the phytohaemagglutinin skin-testing technique in studies of avian immunocompetence. Funct Ecol 13:567-572

Speekmann CL, Bollens SM, Avent SR (2000) The effect of ultraviolet radiation on the vertical distribution and mortality of estuarine zooplankton. J Plankton Res 22:2325-2350

Storz UC, Paul RJ (1998) Phototaxis in water fleas (Daphnia magna) is differently influenced by visible and UV light. J Comp Physiol A 183:709-717

Stuart SN, Chanson JS, Cox NA et al (2004) Status and trends of amphibian declines and extinctions worldwide. Science 306:1783-1786

Takagi T, Tamura Y, Weihs D (2013) Hydrodynamics and energysaving swimming techniques of Pacific bluefin tuna. J Theor Biol 336:158-172

Talentino KA, Landre E (1991) Comparative development of two species of sympatric ambystoma Salamanders. J Freshw Ecol 6:395-401

Tevini M (1993) UV-B radiation and ozone depletion: effects on humans, animals, plants, microorganisms and materials. Lewis Publishers, Boca Raton

Tietge JE, Diamond SA, Ankley GT et al (2001) Ambient solar UV radiation causes mortality in larvae of three species of Rana under controlled exposure conditions. Photochem Photobiol $74: 261-268$

Tsui MTK, Chu LM (2003) Aquatic toxicity of glyphosate-based formulations: comparison between different organisms and the effects of environmental factors. Chemosphere 52: $1189-1197$

Urban MC (2008) Salamander evolution across a latitudinal cline in gape-limited predation risk. Oikos 117:1037-1049

Urban MC (2010) Microgeographic adaptations of spotted salamander morphological defenses in response to a predaceous salamander and beetle. Oikos 119:646-658

Vinebrooke RD, Leavitt PR (1996) Effects of ultraviolet radiation on periphyton in an alpine lake. Limnol Oceanogr 41:1035-1040

Wang N, Besser JM, Buckler DR et al (2005) Influence of sediment on the fate and toxicity of a polyethoxylated tallowamine surfactant system (MON 0818) in aquatic microcosms. Chemosphere 59:545-551

Whiteman HH, Wissinger SA, Denoël M et al (2012) Larval growth in polyphenic salamanders: making the best of a bad lot. Oecologia 168:109-118

Wilga CD, Lauder GV (2001) Functional morphology of the pectoral fins in bamboo sharks, Chiloscyllium plagiosum: benthic vs pelagic station-holding. J Morphol 249:195-209 
Williamson CE (1995) What role does UV-B radiation play in freshwater ecosystems? Limnol Oceanogr 40:386-392

Wojtaszek BF, Staznik B, Chartrand DT et al (2004) Effects of Vision herbicide on mortality, avoidance response, and growth of amphibian larvae in two forest wetlands. Environ Toxicol Chem $23: 832-842$
Worrall JJ, Harrington TC (1988) Etiology of canopy gaps in sprucefir forests at Crawford Notch, New Hampshire. Can J For Res 18:1463-1469

Zaga A, Little EE, Rabeni CF, Ellersieck MR (1998) Photoenhanced toxicity of a carbamate insecticide to early life stage anuran amphibians. Environ Toxicol Chem 17:2543-2553 